\title{
Proteomic Profiles of Young Adults with Acute Myocardial Infarction
}

Norbaiyah Mohamed Bakrim ${ }^{1}$, Azarisman Shah Mohd Shah ${ }^{2}$, Aida Nur Sharini Mohd. Shah $^{2}$, Norlelawati A. Talib ${ }^{3}$, Jamalludin A. Rahman ${ }^{4}$, Noraslinda Muhamad Bunnori $^{5}$, Mohd Yusri Idorus ${ }^{6}$, Aszrin Abdullah ${ }^{1}$

${ }^{1}$ Department of Basic Medical Science, Kulliyyah of Medicine, International Islamic University Malaysia

${ }^{2}$ Department of Internal Medicine, Kulliyyah of Medicine, International Islamic University Malaysia

${ }^{3}$ Department of Pathology and Laboratory Medicine, Kulliyyah of Medicine, International Islamic University Malaysia

${ }^{4}$ Department of Community Medicine, Kulliyyah of Medicine, International Islamic University Malaysia

${ }^{5}$ Department of Biotechnology, Kulliyyah of Science, International Islamic University Malaysia

${ }^{6}$ Institute of Medical Molecular Biotechnology, Faculty of Medicine, UiTM Sungai Buloh

Presenter: Norbaiyah Mohamed Bakrim

Introduction: The incidence of acute myocardial infarction (AMI) in young adults is increasing. However, a molecular study focusing on the pathophysiological changes in young $\mathrm{AMI}$ remains limited. This study aims to examine the proteomic profile of young adults with AMI compared to control subjects. We also hope to identify disease-specific protein biomarkers that contribute to the development of $\mathrm{AMI}$ in the young. Materials and Methods: Pooled plasma protein from $10 \mathrm{AMl}$ patients aged 18 to 45 years and 10 age, gender and race-matched volunteers were separated using two dimensional electrophoresis (2-DE). The protein spots were analysed using the PD Quest analysis software. The protein spots that were found to have been expressed differently between the two groups were identified by Matrix Assisted Laser Desorption/lonization Time of Flight (MALDI-TOF) Mass Spectrometry. Results: There were three differently expressed protein spots, namely Apolipoprotein Al (Apo Al), Apolipoprotein AIV (Apo AIV) and Haptoglobin. The expressions of these proteins were found to be increased in young patients with AMI compared to control subjects (p\&lt; 0.05). Conclusion:The up-regulation of Apo Al, Apo AIV and Haptoglobin in AMI patients could be in response to the inflammatory process associated with the recent cardiac event. The current study seems to reveal a significant function of these proteins during the acute phase response. Thus, Apo Al, Apo AIV and Haptoglobin are potential new biomarkers for young AMI. 